ECONOM Y A N D S OCIET Y 



\title{
ECONOMY AND SOCIETY
}

A New Translation

\author{
M A X W E B E R
}

Edited and translated by

K E I T H T R I B E

\author{
III \\ III \\ Harvard University Press \\ Cambridge, Massachusetts \\ London, England \\ 2019
}


Copyright $\odot 2019$ by the President and Fellows of Harvard College All rights reserved

Printed in the United States of America

First printing

Photo: Max Weber/Hulton Archive/Getty Images

Design: Jill Breitbarth

9780674240834 (EPUB)

9780674240841 (MOBI)

9780674240827 (PDF)

The Library of Congress has cataloged the printed edition as follows:

Names: Weber, Max, 1864-1920, author.| Tribe, Keith, editor, translator.

Title: Economy and society. I : a new translation / Max Weber; edited and translated by Keith Tribe.

Other titles: Soziologische Kategorienlehre. English

Description: Cambridge, Massachusetts : Harvard University Press, 2019. | Includes bibliographical references and index.

Identifiers: LCCN 2018030731 | ISBN 9780674916548 (alk. paper)

Subjects: LCSH: Economics. | Sociology. | Economics-Sociological aspects.

Classification: LCC HB175 .W36413 2019 | DDC 306.3-dc23 LC record available at https://lccn.loc.gov/2018030731 